\title{
Embodied Energy Versus Operational Energy. Showing The Shortcomings Of The Energy Performance Building Directive (EPBD)
}

\author{
F. Pacheco-Torgal ${ }^{1, a}$, Joana Faria ${ }^{2, b}$ and Said Jalali ${ }^{3, c}$ \\ ${ }^{123}$ Research Unit C-TAC, Sustainable Construction Group, University of Minho, \\ Guimarães, Portugal \\ a torgal@civil.uminho.pt, bjoanaffaria@gmail.com, csaid@ civil.uminho.pt
}

Keywords: Embodied energy; operational energy; energy efficiency; building materials

\begin{abstract}
Energy is a key issue for Portugal, it is responsible for the higher part of its imports and since almost $30 \%$ of Portuguese energy is generated in power stations it is also responsible for high $\mathrm{CO}_{2}$ emissions. Between 1995 and 2005 Portuguese GNP rise 28\%, however the imported energy in the same period increased $400 \%$, from 1500 million to 5500 million dollars. As to the period between 2005 and 2007 the energy imports reach about 10,000 million dollars. Although recent and strong investments in renewable energy, Portugal continue to import energy and fossil fuels. This question is very relevant since a major part of the energy produced in Portugal is generated in power plants thus emitting greenhouse gases (GHGs). Therefore, investigations that could minimize energy use are needed.

This paper presents a case study of a 97 apartment-type building $\left(27.647 \mathrm{~m}^{2}\right)$ located in Portugal, concerning both embodied energy as well as operational energy (heating, hot water, electricity). The operational energy was an average of $187,2 \mathrm{MJ} / \mathrm{m}^{2} / \mathrm{yr}$ and the embodied energy accounts for aprox. $2372 \mathrm{MJ} / \mathrm{m}^{2}$, representing just $25,3 \%$ of the former for a service life of 50 years. Since Portuguese energy efficiency building regulation made under the Energy Performance Building Directive (2002/91/EC-EPBD) will lead to a major decrease of operational energy this means that the energy required for the manufacturing of building materials could represent in a near future almost $400 \%$ of operational energy. Replacement up to $75 \%$ of Portland cement with mineral admixtures could allow energy savings needed to operate a very high efficient 97 apartment-type building during 50 years.
\end{abstract}

\section{Introduction}

Growing global demand for energy is a major cause for unsustainable development of our Planet. It is estimated that by 2030 energy demand should grow about $40 \%$, reaching 8.16 billion toe [1].

Portugal has a high energy consumption which accounts for nearly $60 \%$ of its total imports. Between 1995 and 2005 Portuguese GNP rise 28\%, however the imported energy in the same period increased $400 \%$, from 1500 million to 5500 million dollars. As to the period between 2005 and 2007 the energy imports reach about 10,000 million dollars.

Although recent and strong investments in renewable energy, Portugal continue to import energy and fossil fuels. This question is very relevant since a major part of the energy produced in Portugal is generated in power plants thus emitting greenhouse gases (GHGs). This GHG emissions compromises previous commitments under the Burden Sharing Agreement, defined within the European Community. Portugal emissions of $\mathrm{CO}_{2} \mathrm{e}$ (which includes all GHG gases) in 1990 were $60 \mathrm{Mt} / \mathrm{yr}$, and the individual target for Portugal emissions for 2010 could not overpass $76 \mathrm{Mt}$. However, in 2001 the emissions of $\mathrm{CO}_{2} \mathrm{e}$, had already reached $82 \mathrm{Mt}, 36 \%$ above the maximum.

Given that the residential sector consumes $40 \%$ of all the energy produced throughout its life cycle, it is rather obvious that this sector could allow high energy savings. Cepinha et al. [3] argue that energy efficiency could easily lead to a reduction by one fifth of the energy consumed in the residential sector implying a reduction of $340 \mathrm{Mt}$ of carbon dioxide. The measures taken in recent years under the EPBD, aimed at reducing the operational energy of the buildings (heating, hot water, electricity etc).This is because it was accepted that the largest energy part were due to 
operational energy. And indeed in inefficient buildings, the embodied energy represents just 10$15 \%$ of operational energy. However, as buildings become more energy efficient operational energy will be reduced and therefore embodied energy will become increasingly predominant.

Thormark [4] studied one of the buildings with the lowest energy consumption in Sweden $\left(45 \mathrm{kWh} / \mathrm{m}^{2}\right)$ stating that the embodied energy in materials, for a lifespan of 50 years may represent $45 \%$ of operational energy.

Dimoudi \& Tompa [5] reported that the embodied energy in office buildings can range between $13 \%$ to $19 \%$ of operational energy for a lifetime of 50 years. The operational energy versus embodied energy them it is then a controversy issue.

The present manuscript analyses energy consumption of a building with 97 apartments (27.647 $\mathrm{m}^{2}$ ). Operational energy and embodied energy are compared in order to highlight the factors that could lead to high energy savings.

\section{The case study characteristics}

The case study building is located in the Oporto region and consists of a 97 apartment-type building with a total area of $27.647 \mathrm{~m}^{2}$. The operational energy of the building was estimated from electricity and gas consumption of eight apartments. Data of electricity and gas consumption is present in Table 1.

Table 1. Operational energy consumption in 8 apartments

\begin{tabular}{|c|c|c|c|c|}
\hline Apartment & $\begin{array}{c}\text { Electricity } \\
{[\mathrm{kWh} / \mathrm{yr}]}\end{array}$ & $\begin{array}{c}\text { Gas * } \\
{[\mathrm{kWh} / \mathrm{yr}]}\end{array}$ & $\begin{array}{c}\text { Area } \\
{\left[\mathrm{m}^{2}\right]}\end{array}$ & $\begin{array}{c}\text { Total } \\
{[\mathrm{kWh} / \mathrm{yr}]}\end{array}$ \\
\hline 1 & 3966 & - & 75 & 3966 \\
\hline 2 & 6772 & - & 97 & 6772 \\
\hline 3 & 2190 & 4287 & 200 & 6477 \\
\hline 4 & 1095 & 3787 & 135 & 4882 \\
\hline 5 & 2249 & 8600 & 138 & 10849 \\
\hline 6 & 1095 & 9056 & 120 & 10151 \\
\hline 7 & 913 & 1278 & 75 & 2191 \\
\hline 8 & 2107 & 9678 & 180 & 11785 \\
\hline
\end{tabular}

* Gas consumption was obtained from gas volume using the conversion factor $11,6180 \mathrm{kWh} / \mathrm{m}^{3}$ (Source EDP)

Using the median consumption and the median area we obtain respectively the value of $6625 \mathrm{kWh}$ and $127.5 \mathrm{~m}^{2}$, which will provide a unitary consumption of $52 \mathrm{kWh} / \mathrm{m}^{2} / \mathrm{yr}$. Converting this value in MJ using the factor 0.2778 [6], we get $187.2 \mathrm{MJ} / \mathrm{m}^{2} / \mathrm{yr}$ which represents $9359 \mathrm{MJ} / \mathrm{m}^{2}$ in a $50 \mathrm{yr}$ service life.

\section{Embodied energy}

Current situation. The embodied energy was assessed for the following parts: concrete; steel; masonry; ceilings and roofs; doors and windows, mortars, renders, rockwool and cork insulation. Embodied energy was assess applying embodied energy coefficients (cradle to gate scenario) collected from two databases [7,8] to the mass of the materials responsible for the higher part of embodied energy (Table 2). Figure 1 shows the embodied energy (in percentage) of construction materials, corresponding to a total of 58,249,336 MJ. Embodied energy in concrete represents 70\% of the total; therefore, high energy reductions can only occur by lowering the energy in this material. Assuming an average distance between the factory gate and the construction site of $30 \mathrm{~km}$ and an average transport energy of $1.5 \mathrm{MJ} /$ (ton.km) we get 1,515,195 MJ for building materials transportation. 
Table 2. Materials and embodied energy coefficients (EI)

\begin{tabular}{|c|c|c|c|}
\hline Material & Quantity & EI (MJ/kg) & Ref. \\
\hline Aluminium for windows and doors & 24,3 ton. & 184 & {$[7]$} \\
\hline Mortars and renders & $1775 \mathrm{~m}^{3}$ & 1 & {$[7]$} \\
\hline Glass & $64798 \mathrm{~m}^{2}$ & 8 & {$[7]$} \\
\hline Rockwool insulation & $3622 \mathrm{~m}^{2}$ & 16 & {$[7]$} \\
\hline Clay brick & $324063 \mathrm{un}$ & 3 & {$[7]$} \\
\hline Cork insulation & $12978 \mathrm{~m}^{2}$ & 4 & {$[7]$} \\
\hline Concrete & 31000 ton. & 0,99 & {$[8]$} \\
\hline Reinforced steel & 1260 ton. & 8,8 & {$[8]$} \\
\hline
\end{tabular}

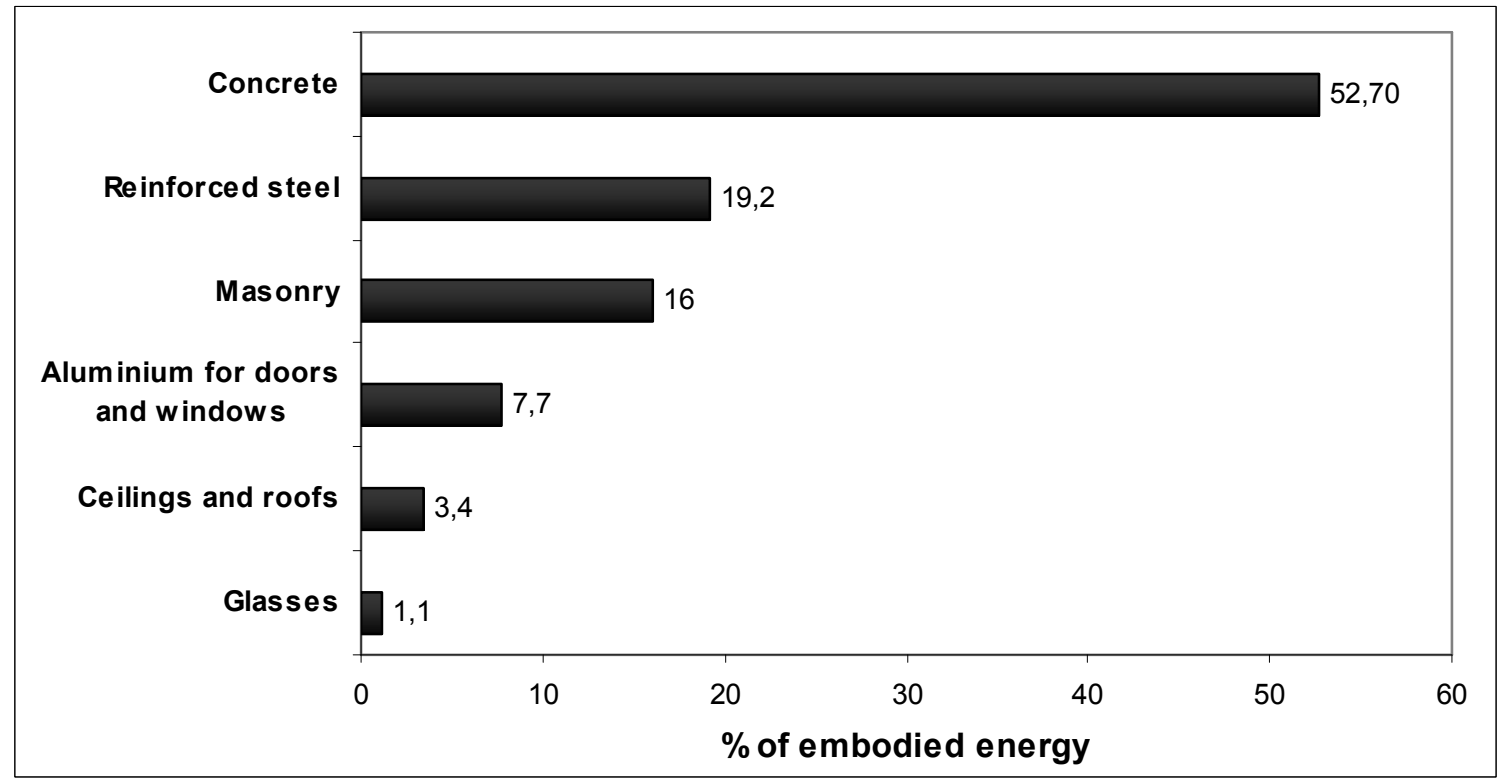

Figure 1.Embodied energy of the different materials

For the energy used during construction of the building an estimate of $10 \%$ was assumed of the energy production [9], which gives a value of 5,824,933 MJ. Then a total of 65,589,464 MJ arise, which corresponds to $2372 \mathrm{MJ} / \mathrm{m}^{2}$. This represents $25.3 \%$ of operational energy for a period of 50 years, which does not differ much from the estimation presented by Dimoudi \& Tompa [5].

Buildings with high and very high energy efficiency. If the building consumed just $28 \mathrm{kWh} / \mathrm{m}^{2}$ due to the inclusion of some measures under the EPBD leading to a more energy efficient thermal envelope as proposed by others [10], then a $100.1 \mathrm{MJ} / \mathrm{m}^{2} / \mathrm{yr}$ unitary consumption could be achieved for operational energy. This would imply that the ratio embodied energy/operational energy climbed to $47.1 \%$ for a lifetime of the building of 50 years. However, if the building used just the energy needed for Portuguese AA+ class buildings of about $12 \mathrm{kWh} / \mathrm{m}^{2}$ [11] this would represent $600 \mathrm{MJ} / \mathrm{m}^{2}$ for the 50 -year lifespan. This value is well below the amount of energy embodied, accounting for just $25 \%$ of it.

Building materials with lower embodied energy. One option to reduce embodied energy is by using high volume cement replacement mineral admixtures. Although current cement replacement levels in Portugal are set at 30\%, some investigations indicate the possibility of producing high performance concrete with high volumes replacement of $60 \%$ fly ash [12], or even $80 \%$ blast furnace slag [13].

Another way to reduce embodied energy could include reinforced steel replacement by bamboo bars. Investigations in this area are very promising and show a decrease of the adhesion between concrete/bamboo that can easily be overcome with the use of pins embedded in the bamboo bars 
[14-16]. With respect to the durability of bamboo based concrete, some authors reported a case of a bamboo based concrete structure that showed no sign of degradation after 15 years of service life [17]. Others confirm the high durability of concrete based bamboo [18].

For the present case study using a concrete with a replacement up to $75 \%$ of Portland cement with mineral admixtures (Embodied Energy $=0.53 \mathrm{MJ} / \mathrm{kg}$ ) will allow savings of 16.43 million MJ. So the total for the materials considered above were $49,159,464 \mathrm{MJ}$, corresponding to a unitary value of $1778 \mathrm{MJ} / \mathrm{m}^{2}$. This means that the mere change of concrete composition would mean a $25 \%$ embodied energy reduction. Almost as much as the energy used by a AA+ class 97 apartment-type building during 50 years. As for carbon dioxide emissions using this high volume cement replacement would represent saving 265 tones of $\mathrm{CO}^{2}$ (the conversion rate between $\mathrm{MJ}$ and $\mathrm{CO}^{2}$ was already used by others [19]).

Other authors mentioned that increasing the use of wood for building construction would reduce carbon emissions by nearly 50\% [20]. Those findings show the urgency of using low embodied energy building materials as a good way to reduce energy consumption in the building sector.

\section{Further considerations}

Suggestions regarding the need for EPBD to encompass embodied energy have already been done by Szalay [21]. Also recent work done by others [22], recognize that energy savings by means of more efficient thermal insulation, as well as increasing renewable energy is an insufficient approach. Strangely, the proposal for the new EPBD [23] recently approved keeps focusing on operational energy reduction and also on renewable energy sources produced on site saying nothing about the importance of using low embodied energy building materials. As a consequence the building sector will continue to have no stimulus to choose low embodied energy materials.

\section{Conclusions}

High energy consumption is one of the most serious problems faced by Portugal. It represents a serious economic constraint and also means GHG emissions, which could involve financial penalties in a near future. Currently the largest energy consumption in the building sector are due to operational energy. However, as the legislation on energy efficiency lead to a building sector with minimal energy consumption, further energy reduction can only be achieved by using low embodied energy building materials. The use of concrete with high levels of cement replacement by pozzolanic additives will in the short term be the most obvious step in that direction.

\section{References}

[1] World Energy Outlook. ISBN 978-92-64-06130-9, IEA (2009)

[2] EUROSTAT - Energy Dependency Statistics (2007)

[3] E.Cepinha, P. Ferrão, S. Santos, The certification as an enterprise strategy of the real estate sector: a national scope analysis, in: International Congress Sustainable Construction, Materials and Practices - Challenge of the Industry for the New Millennium: ISBN 978-158603-785-7, Lisbon, 2007, pp.912-917.

[4] C. Thormark, A low energy building in a life cycle - its embodied energy, energy need for operation and recycling potential, Building and Environment 37 (2002) 429-435.

[5] A. Dimoudi, C. Tompa, Energy and environmental indicators related to construction of office buildings, Resources Conservation and Recycling 53 (2008) 86-95.

[6] B. Berge, The Ecology of Building Materials, $2^{\circ}$ Edition, Architectural Press, ISBN 978-185617-537-1, Elsevier Science, 2009.

[7] U. Wellington, Table of embodied energy coefficients, Centre for Building Performance, 2005.

[8] G. Hammond, C. Jones, Inventory of carbon and Energy (ICE), 2008, Version 1,6a. Information on http:/www.bath.ac.uk/mech-eng/sert/embodied 
[9] Forintek, Raw material balances, energy profiles and environmental unit factor estimates for structural wood products/structural steel products/cement and structural concrete products. Vancouver, Canada, 1993.

[10] S. Silva, M. Almeida, Energy consumption and economic performance for different construction measures, Civil Engineering Journal, University of Minho 18 (2003) 45-62. (only in Portuguese)

[11] J. Manso, Evaluation of energy and environmental performance in household buildings, Master Thesis, University of Aveiro, Portugal, 2005 (only in Portuguese).

[12] A. Camões, High performance concrete with high fly ash volume replacement, $\mathrm{PhD}$ Thesis, University of Minho, Portugal, 2002 (only in Portuguese).

[13] E. Guneyisi, M. Gesoglu, A study on the durability properties of high-performance concretes incorporating high replacement levels of slag, Materials and Structures 41,2008, 479-493.

[14] L. Khare, Performance evaluation of bamboo reinforced concrete beams, Master of Science in Civil Engineering, University of Texas, 2005.

[15] Y. Jung, Investigation of bamboo as reinforcement in concrete, Master of Science in Civil and Environment Engineering, University of Texas, 2007.

[16] G. Ferreira, Concrete beams with bamboo bars as reinforcement, PhD Thesis, UNICAMP, Brazil, 2007 (only in Portuguese).

[17] K. Ghavami, Bamboo as reinforcement in structure concrete elements, Cement \& Concrete Composites 27 (2005) 637-649.

[18] L. Lima, F. Willrich, N. Barbosa, M. Rosa, B. Cunha, Durability analysis of bamboo as concrete reinforcement, Materials and Structures 41(2008) 981-989.

[19] M. Gonzalez, J. Navarro, Assessment of the decrease of $\mathrm{CO}_{2}$ emissions in the construction field through the selection of materials, Building and Environment 41 (2006) 902-909.

[20] T. Goverse, M. Kekkert, P. Groenewegen, E. Worrell, R.Smits, Wood innovation in the residential construction sector: opportunities and constraints, Resources, Conservation and Recycling 34 (2001) 53-74.

[21] A. Szalay, What is missing from the concept of the new European Building Directive, Building and Environment, 42 (2007) 1761-1769.

[22] F.Sandrolini, E. Franzoni, Embodied energy of building materials: A new parameter for sustainable architectural design, International Journal of Heat and Technology 27 (2010) 163167.

[23] European Parliament, Report on the proposal for a directive of the Euroepan Parliament and of the council on the energy performance of buildings. COM, 2008, 0780-C6-0413/2008. 